\title{
PRIVATIZAÇÃO DA EDUCAÇÃO NA AMÉRICA LATINA: ESTRATÉGIAS RECENTES EM DESTAQUE
}

\author{
APRESENTAÇÃO
}

\section{$\mathrm{P}$}

arodiando o 'Manifesto do Partido Comunista' (MARX; ENGELS, 1988), pode-se dizer que um espectro ronda as políticas educacionais no mundo e, infelizmente, não se trata do espectro do comunismo mas, sim, da privatização. Ele decorre da busca incessante do capital por novas formas de acumulação e tem assumido diferentes formas e arranjos em países diversos. Em sua onda mais recente, irradiando os modelos de 'Voucher' e de 'Charter School originários dos EUA, os arranjos privatizantes, que tiveram no Chile, ainda na ditadura de Pinochet, um laboratório privilegiado, espalham-se com particular intensidade pelos países latino-americanos.

Reagindo a essa tendência, ativistas e pesquisadores articulam-se em diversas frentes, uma das quais pode ser ilustrada neste dossiê, o qual se origina da atuação de um conjunto de pesquisadores e ativistas que vêm analisando e resistindo aos distintos processos pelos quais em nosso continente e, a partir do do século passado, a educação vem sendo privatizada.

Os artigos que integram este esforço de reflexão decorrem de pesquisas realizadas em campos distintos e analisam, por distintas abordagens, variadas dimensões de um mesmo processo: a privatização da educação. Trata-se de pocesso entendido, de forma abrangente, como a trasferência, por parte do poder público, da responsabilidade pela efetivação do direito à educação formal para o setor privado. Para Levin (2010), corresponderia à transferência de atividades, bens e responsabilidades das instituições e organizaçóes governamentais/públicas a setores privados, com ou sem fins de lucro.

Os mecanismos pelos quais essa transferência vem ocorrendo nos diferentes países da região, obviamente, não se apresentam de forma linear ou homogênea, uma vez que resultam de distintos contextos históricos, os quais permitiram variaçóes tão diversas quanto a consolidação de sistemas públicos de educação básica desde o século XIX, em países como a Argentina ou Uruguai, bem como a introdução radicalizada de orientaçôes neoliberais para a organização da educação nacional já nos anos 1980, observada no Chile, ou ainda a inscrição recente da educação como direito público subjetivo, e, portanto, de responsabilidade do Estado, apenas ao final dos anos 1980, observada no Brasil.

DOI: 10.1590/ES0101-73302016162765 
Ainda assim, um traço de unidade pode ser percebido quando se mira para a presença originária do subsídio público à igreja católica como condição para a oferta da educação em toda a regiáo, desde os primórdios da colonização, como aconteceu, por exemplo, no Brasil. Tal condição de origem, por vezes, inibe a percepçáo da educação básica como bem público e, por esse motivo, como um direito e não como um privilégio daqueles que podem "escolher", consigna, entre nós, publicizada por Anisio Teixeira (2007), cujo conteúdo se viabiliza por meio da ação do Estado, democraticamente controlada pela sociedade.

Um segundo aspecto a ser assinalado, quando da análise das estratégias de privatização, refere-se à falta ou diminuição do controle social sobre a gestão da educação e sobre a destinação dos fundos públicos, na medida em que os agentes privados, alçados a protagonistas dessas políticas, especialmente quando movidos pelo lucro, não têm interesse em publicizar informações, que passam a ser consideradas "privadas" embora envolvam o interesse público.

Os artigos que integram este dossiê têm como foco central a privatização da educação básica, embora para o Brasil também se analise a destinação de recursos públicos para os setores privados que atuam na educação superior. Os autores analisam as estratégias distintas pelas quais tomam forma os processos de subordinação dos direitos e das políticas sociais a interesses privados, em alguns casos globalmente articulados. Obviamente, considerando que a tendência à privatização encontra-se em processo, os estudos não pretendem abarcar a multiplicidades de formas pelas quais o capital, direta ou indiretamente, vem se apropriando das diversas dimensóes da educação pública, aqui entendida como tarefa estatal.

Dentre os trabalhos que passamos a apresentar, dois artigos buscam uma análise mais panorâmica sobre as diferentes formas de privatização da educação na América Latina e no Caribe, enquanto seis aprofundam-se em aspectos específicos do fenômeno, em diferentes países da região.

Com vistas a compor um quadro mais geral sobre as estratégias de privatização da educação básica, este dossiê tem início com o artigo de Camilla Croso C. da Silva e Giovanna Mode Magalhães, ambas da Campanha Latino-Americana pelo Direito à Educação (CLADE), intitulado "Privatização da educação na América Latina e no Caribe: tendências e riscos para os sistemas públicos de ensino", em que as autoras apresentam uma visão ampliada das formas pelas quais a educação básica tem sido privatizada neste início de século XXI. O estudo tomou por base a pesquisa Tendencias de la Privatización de la Educación en América Latina y el Caribe, coordenada pela própria CLADE e desenvolvida por meio da análise da legislaçáo dos países e de entrevistas com ativistas dos movimentos sociais e de pesquisadores latinoamericanos ligados à luta pelo direito à educação. 
O texto seguinte, "Mediatización de los procesos de privatización de - y en - la educación en América Latina y el Caribe: un estudio de los discursos mediáticos”, elaborado por Eva da Porta (pesquisadora do Centro de Estudios Avanzados - Universidad Nacional de Córdoba) e Maria Cianci (integrante da Asociación Latinoamericana de Educación Radiofónica), propóe-se a analisar os diferentes modos como os discursos midiáticos hegemônicos tendem a favorecer a aceitação pública da privatização educativa. As autoras analisam as publicaçóes relativas à educação em periódicos de grande circulação nacional em quatro países da região: Argentina, Chile, México e Equador. $\mathrm{O}$ trabalho considera também o conteúdo disseminado em páginas de notícias e de organizaçóes da sociedade civil que se colocam em perspectiva contra-hegemônica.

Focalizando a experiência argentina de privatização da gestão educacional, o artigo "De las Rocallosas a los Andes: el experimento de escuelas charter em el contexto politico argentino", de autoria de Mauro Moschetti (Universidade Autônoma de Barcelona) e Verônica Gottau (Universidade Torcuato Di Tella de Buenos Aires), descreve e analisa o projeto já extinto desenvolvido na província de San Luis, denominado Escuelas Experimentales Autogestionadas. Segundo os autores, trata-se de projeto inspirado no modelo de "charter schools", modelo disseminado nos Estados Unidos, a partir de 1991, que compreende a gestão privada de escolas públicas ou o financiamento público de escolas geridas privadamente, mas cuja oferta deve ser gratuita (WELLS, 1993). A pesquisa envolveu análise documental e entrevistas com idealizadores do projeto, ex-funcionários do $\mathrm{Mi}$ nistério da Educação e associaçóes envolvidas.

Também analisando formas de privatização da gestão da escola pública, o texto "El progresivo encanto por la gestión privada: análisis de los modelos de la gestión público-privada en enseñanza media en Uruguay (2002-2013)", elaborado por Eloísa Bordoli e Stefania Conde, pesquisadoras da Universidade da República do Uruguai, destaca três experiências desenvolvidas em escolas de ensino médio daquele país. A primeira, "Programa Aulas Comunitárias" refere-se à gestão compartilhada entre o Conselho de Educação Secundária e diversas organizaçóes da sociedade civil. Já os modelos "Liceus Jubilar" e "Impulso" se referem a formatos de oferta privada com subsídio público.

Juan Gonzáles, pesquisador da Universidade do Chile, e Diego Parra, da Universidade ARCIS, ambos investigadores da Cooperativa de Trabajadores Centro ALERTA e do Observatório Chileno de Políticas Educativas, assinam o artigo "Privatización de la provisión educativa en Chile: caracterización de los proveedores educativos de una comuna popular urbana”. Neste, os autores analisam os efeitos de treze anos de privatização em uma comuna urbana e popular na região metropolitana de Santiago. Os autores analisam o perfil do crescimento do setor privado, os atores envolvidos, os projetos em disputa e os resultados obtidos. 
Escrito por pesquisadoras vinculadas ao Grupo de Estudos e Pesquisa em Políticas Educacionais (Greppe) — Theresa Adrião (Universidade Estadual de Campinas — Unicamp), Teise Garcia (Universidade de São Paulo — USP — Ribeirão Preto), Regiane Bertagna e Raquel Borghi (estas da Universidade Estadual Paulista Júlio de Mesquita Filho - Unesp - Rio Claro), por Gustavo Paiva (do Observatório da Educação, da Ação Educativa) e por Salomão Ximenes professor da Universidade Federal do ABC — UFABC) —, o artigo "Grupos empresariais na educação básica pública brasileira: limites à efetivação do direito à educação" mapeia e analisa as consequências para a efetivação do direito à educação básica que decorrem da adoção de "sistemas privados de ensino" por redes públicas no Brasil. Adquiridos por governos subnacionais, especialmente os locais, os tais "sistemas privados de ensino" têm se difundido junto às redes públicas desde 1998, caracterizando-se como uma forma de privatização do currículo. A pesquisa caracteriza os principais grupos envolvidos bem como os municípios que contratam tais grupos, apoiando-se em levantamento de fontes primárias disponíveis em sítios oficiais e institucionais, informaçóes coletadas junto aos Tribunais de Contas e entrevistas a gestores municipais.

Ainda sobre o Brasil, o artigo de José Marcelino de Rezende Pinto (USP), "Uma análise da destinação dos recursos públicos, direta ou indiretamente, ao setor privado de ensino no Brasil", analisa os três diferentes mecanismos de repasse de recursos públicos ao setor privado: primeiramente, a destinação direta de recursos, caso do Sistema "S", do Pronatec e de convênios para oferta de educação infantil e educação especial pela iniciativa privada; em segundo lugar, a renúncia fiscal, como é o caso do desconto padrão de imposto de renda da pessoa física para os contribuintes que possuem filhos na rede privada, do Prouni e da isenção de tributos às entidades educacionais sem fins lucrativos; e, também, os subsídios ao financiamento estudantil, como é o caso do FIES. O autor baseia-se em dados e valores disponibilizados por órgãos oficiais e em relatórios de fiscalização do Tribunal de Contas da União.

Por fim, introduz-se um tema pouco analisado na produção brasileira, mas que tem ganhado interesse em outros países. Trata-se da opção das famílias por uma educação doméstica (homeschooling), presente em mais de sessenta países. O tema é abordado no artigo "Homeschooling no Brasil: ampliação do direito à educação ou via de privatização?”, de Luciane Barbosa (Unicamp). Neste trabalho, a autora considera as contradiçóes desta tendência decorrentes da atuação do Estado Democrático de Direito e as possíveis implicaçóes para a privatização da educação.

Com este dossiê, que ora Educação \& Sociedade oferece à comunidade acadêmica, aos educadores e à população em geral, cujo conteúdo articula-se aos temas desenvolvidos no vol. 30, n. 108 deste periódico publicado em 2009, esperamos que se adensem, por meio do acesso a evidências empíricas e reflexóes, o entendimento e os mecanismos de resistência ao fenômeno da privatização em 
suas diferentes nuances. Considerando a relação direta entre o avanço da privatização e o recuo do direito à educação, aqui entendida como direito humano e um bem universal, espera-se que este número se constitua em estímulo para novas pesquisas, bem como em recurso para a luta política de todos aqueles que entendem a educaçáo de qualidade pública e gratuita como um direito de todos os povos a ser assegurado pelo Estado.

\author{
Theresa Adriäo $o^{1}$ \\ José Marcelino de Rezende Pinto ${ }^{2}$
}

\title{
Referências
}

LEVIN, H.M. (ed.) Privatzing Educaction. Can the marketplace deliver choice, efficiency, equity and social cohesion? Westview Press, Cambridge, USA.

MARX, K.; ENGELS, F. Manifesto do Partido Comunista. Sáo Paulo: Global, 1988.

TEIXEIRA, A. Educação não é privilégio. Rio de Janeiro: Editora UFRJ, 2007.

WELLS, A.S. Time to choose. America at the crossroads of schools choice policy. New York: New Frontiers of Educaction, 1993.

\footnotetext{
${ }^{1}$ Universidade Estadual de Campinas, Faculdade de Educação - Campinas (SP), Brasil. E-mail: theadriao@gmail.com

${ }^{2}$ Universidade de São Paulo, Faculdade de Filosofia, Ciências e Letras de Ribeirão Preto - Ribeirão Preto (SP), Brasil.E-mail: jmrpinto@ffclrp.usp.br
} 